\title{
Perbedaan Resiko Gangguan Psikososial pada Remaja Positive Smartphone Addiction dan Negative Addiction di SMA Kota Sungai Penuh Tahun 2019
}

\author{
Edi Efian ${ }^{1}$, Rizanda Machmud ${ }^{2}$, Mahathir $^{3}$, Meri Neherta ${ }^{4}$, Rima Berlian Putri ${ }^{5}$, Fitra Yeni ${ }^{6}$ \\ 1,2,3,4,6Fakultas Keperawatan Universitas Andalas, Limau Manis Padang \\ ${ }^{5}$ Stikes Prima Nusantara Bukit Tinggi \\ Correspondence email: efian82@gmail.com
}

\begin{abstract}
Abstrak. Penggunaan smartphone yang berlebihan akan berisiko kecanduan, kecanduan smartphone akan mempengaruhi kesehatan psikologis yang ber efek lanjut ke gangguan psikososial. Remaja adalah masa rentan yang mudah menerima budaya baru, budaya teknologi smartphone menjadi salah satu yang mengintai remaja. Penelitian ini adalah untuk mengetahui perbedaan resiko gangguan psikososial pada remaja dengan positive smartphone addiction dengan negative smartphone addiction. Penelitian ini merupakan studi kuantitatif dengan desain cross sectional, pengambilan data mengunakan kuesioner smartphone addiction scale (Short-version) dan pediatric symptom checklist (PSC-17), populasi remaja di sekolah menengah atas kota Sungai Penuh, sampel berjumlah 350 orang, variabel yang teliti terdiri dari variable independen smartphone addiction dan variable dependent gangguan psikososial pada remaja. Terdapat perbedaan resiko gangguan psikososial pada remaja, laki-laki 60/25 mengalami gangguan psikososial $(p=0,000)$ OR 3,936. Pada remaja perempuan 50/47 mengalami gangguan psikososial (0.004) OR 2,437. Remaja positive smartphone addiction beresiko lebih besar untuk mengalami gangguan psikososial.
\end{abstract}

Kata kunci: Smartphone addiction; gangguan psikososial

\begin{abstract}
Excessive use of smartphones poses a risk of addiction, smartphone addiction will affect psychological health which has an effect on psychosocial disorders. Teenagers are a vulnerable period that easily accepts new cultures, smartphone technology culture is one that lurks teenagers. Objective: This study is to determine the differences in the risk of psychosocial disorders in adolescents with positive smartphone addiction with negative smartphone addiction. This research is a quantitative study with cross sectional design, data collection using the smartphone addiction scale (Short-version) questionnaire and pediatric symptom checklist (PSC-17), the population of adolescents in high schools in Sungai Penuh city, a sample of 350 people, the conscientious variable consists of the independent variable smartphone addiction and the dependent variable psychosocial disorders in adolescents. There was a difference in the risk of psychosocial disorders in adolescents, 60/25 men experienced psychosocial disorders ( $p=$ $0,000)$ OR 3,936. In adolescent girls 50/47 experience psychosocial disorders (0.004) OR 2,437. Teen positive smartphone addiction is at greater risk for experiencing psychosocial disorders.
\end{abstract}

Keywords: Smartphone addiction; psychosocial disorders

\section{PENDAHULUAN}

Penggunaan smartphone yang berlebihan beresiko akan mengalami smartphone addiction yang berefek ke gangguan psikologis ( $\mathrm{Wu}$, Cheung, $\mathrm{Ku}$, \& Hung, 2013), remaja adalah masa rentan yang mudah menerima budaya baru termasuk perkembangan teknologi smartphone, masa remaja adalah fase jendela yang menerima kondisi baru tanpa filter (Baker, Den, Graham, \& Richardson, 2013), di perlukan pengawasa dari orang tua terhadap remaja dalam penggunaan smartphone (Muflih, Hamzah, \& Puniawan, 2017).

Untuk menghindari dampak psikologis yaitu gangguan psikososial pada remaja di perlukan control orang tua dalam penggunaan smartphone (Ferguson, 2015), penggunaan smartphone dalam waktu yang lama berefek ke fungsi sosial, akademik dan hubungan antara orang tua dengan remaja (Sussman, Harper, Stahl, \& Weigle, 2017).

Remaja yang mengalami gangguan psikososial membutuh dukungan lingkungan dalam pemulihan, seperti lingkungan keluarga dan sekolah (Lee, Bejerano, Han, \& Seok, 2019). Orang tua berpengaruh secara emosional dalam perkembangan psikologis remaja, orang tua harus mampu memahami perkembangan remaja (Aboobaker, Jangam, Vijay, Amaresha, \& Jose, 2019).

Remaja lebih menyukai bergaul dengan teman sebaya atau peer grup, merasa mempunyai kesamaan, teman sebaya adalah aspek terpenting dalam kehidupan remaja (Santrock, 2014). Faktor dukugan lingkungan masyarakat dan sekolah mempengaruhi perkembangan psikososial ramaja (Perez et al., 2017). lingkungan sekolah dan masyarakat perlu dilibatkan pemulihan remaja yang mengalami gangguan psikososial, orang tua melibatkan teman sebaya dalam terapi keluarga karna lebih di percayai oleh remaja (Yeon, Yop, \& Won, 2018).

Kebijakkan orang tua yang derapkan dalam keluarga mempengaruhi perkembangan psikososial remaja (Aboobaker et al., 2019). Dalam pengenalan smartphone pada remaja akan menentukan remaja mengalami smartphone addiction atau tidak (Cho \& Lee, 2017), remaja yang mengalami smartphone addiction cenderung menghindar dari teman sebayanya karna terobsesi dengan smartphone yang mempengaruhi perkembangan sosialnya (Young, 2015).

Beberapa penelitian bahwa remaja yang positif smartphone addiction mempengaruhi psikososial (Chung, Sum, Sc, Chan, \& Soc, 2019), penelitian yang di lakukan oleh Schneider (2013), masa remaja adalah masa rentan yang mudah menerima budaya baru termasuk perkembangan teknologi smartphone. Remaja laki-laki cenderung mudah untuk mengalami smartphone addiction (Lukman, 2018).

Penelitian yang di di India lakukan oleh Nayak ( 2018) remaja laki-laki cenderung lebih mudah untuk mengalami smarphone addiction dari pada perempuan, sedangakan psikososial pada remaja lebih banyak 
disebabkan oleh hbungan dengan orang tua, persepsi, gaya hidup, sosial ekonomi dan stress psikologis (Wayan Diah Anima, 2014).

Penelitian ini untuk mengetahui perbedaan resiko gangguan psikososial akibat smartphone addiction.

\section{METODE PENELITIAN}

Jenis penelitian ini adalah peneltian kuantitatif dengan desain cross sectional.

\section{Populasi dan sampel}

Populasi dalam penelitian ini adalah seluruh siswa-siswa Sekolah Menengah atas Kota Sungai Penuh, Provinsi Jambi. sampel di ambil dengan proportional random sampling. Jumlah sampel dalam penelitian ini 350 siswa kelas 12

\section{Pengumpulan data}

Sebelum penelitian peneliti menjelaskan tujuan dan maksud penelitian dan tahap-tahap penelitian. $R e-$ sponden di minta kesediannya menjadi responden tanpa paksaan, dan responden membaca infoment consent dan menanda tangani kesediaan menjadi responden. Data di kumpulkan selama dua bulan dengan mengunjungi sekolah yang menjadi tujuan penelitian, dan responden mengisi kuesioner secara langsung. Penelitian ini telah lolos uji etik fakultas kedoteran Universitas Andalas Nomor:158/KEP/FK/2019 pada tanggal 26 Maret 2019.

\section{Instrument penelitian}

Instrument penelitian menggunakan kuesioner smartphone addiction scale -short version yang di pertama kali oleh Abreu,( 2011), dan di kembangkan kembali oleh Kwon, Kim, Cho, \& Yang,9 2013) dan kuesiner pediatric symptom checklist (psc -17) yang pertama kali di perkenalkan Jellinek et al.,( 1991), dan dikembangkan oleh Comer \& Kelleher, (2014)

Instrument smartphone addiction scale-short verson digunakan untuk mendeteksi smartphone addction, terdiri dari sepuluh pertanyaan, dengan pilihan jawaban skor 1 "sangat setuju" sampai dengan skor 6 untuk " sangat tidak sutuju" dengan total skor untuk laki-laki <31 negatif smartphone addiction dan $\geq 31$ Positif smartphone addiction dan untuk perempuan < 33 Negative smartphone addiction dan $\geq 33$ positif smartphone addiction.

Instrumen pediatric symptom checklist (psc-17), di gunakan untuk mendeteksi gangguan psikososial terdiri dari 17 pertanyaan, dengan pilihan jawaban $\mathrm{O}$ untuk " tidak pernah", 1 untuk "Kadang-kadang" dan 2 untuk jawaban "Sering".

Hasil uji validitas di lakukan di SMK N 1 Sungai Penuh dengan 50 responden, uji validitas menggunakan corrected-item total correction dengann nilai $r$ hitung $\geq r$ tabel $(0,36)$ maka dintakan valid.

\section{Analisis data}

Untuk hubungan antar variable data di analisis menggunakan tes chi-squre, dengan level signifikani $\alpha=0,05$ untuk mengetahui hubungan smartphone addiction dengan gangguan psikososial pada remaja.

\section{HASIL DAN PEMBAHASAN}

Tabel 1. Hasil analisis univariat distribusi frekuensi jenis kelamin

\begin{tabular}{clcc}
\hline No & Karakteristik Jenis Kelamin & Frekuensi & $\%$ \\
\hline 1 & Laki-laki & 151 & 43,1 \\
2 & Perempuan & 199 & 56,9 \\
& Jumlah & 350 & 100 \\
\hline
\end{tabular}

Tabel 2. Hasil analisis univariat distribusi frekuensi

\begin{tabular}{clcc}
\multicolumn{3}{c}{ smartphone addiction } \\
\hline No & Karakteristik & $\mathrm{F}$ & $\%$ \\
\hline 1 & $\begin{array}{l}\text { Positive } \\
\text { smartphoe addiction }\end{array}$ & 182 & 52,0 \\
2 & $\begin{array}{l}\text { Negative } \\
\text { smartphone addiction }\end{array}$ & 168 & 48,0 \\
$\quad$ Total & 350 & 100 \\
\hline
\end{tabular}

Tabel 3. Hasil analisis univariat gangguan psikososial

\begin{tabular}{clcc}
\hline No & Karakteristik & $\mathrm{F}$ & $\%$ \\
\hline 1 & Gangguan psikososial & 166 & 47,4 \\
2 & Tidak gangguan psikososial & 184 & 52,6 \\
& Total & 350 & 100 \\
\hline
\end{tabular}

Tabel 4. Hasil analisis bivariate hubungan smartphone addiction dengan gangguan psikososial berdasarkan jenis kelamin

\begin{tabular}{|c|c|c|c|c|c|c|}
\hline & Jenis_Kelamin & $\begin{array}{l}\text { Gangguan } \\
\text { psikososial }\end{array}$ & $\begin{array}{l}\text { Tidak gangguan } \\
\text { psikososial }\end{array}$ & Total & $\mathrm{p}$-value & $\begin{array}{c}\text { OR } \\
\text { (Cl 95\%) }\end{array}$ \\
\hline \multirow[t]{6}{*}{ Laki laki } & Positive smartphone addiction & 60 & 25 & 85 & & \\
\hline & & $70,6 \%$ & $29,4 \%$ & $100,0 \%$ & & \\
\hline & Negative smartphone addiction & 25 & 41 & 66 & 0.000 & 3.936 \\
\hline & & $37,9 \%$ & $62,1 \%$ & $100,0 \%$ & & \\
\hline & Total & 85 & 66 & 151 & & \\
\hline & & $56,3 \%$ & $43,7 \%$ & $100,0 \%$ & & \\
\hline \multirow[t]{6}{*}{ Perempuan } & Positive smartphone addiction & 50 & 47 & 97 & & \\
\hline & & $51,5 \%$ & $48,5 \%$ & $100,0 \%$ & & \\
\hline & Negative smartphone addiction & 31 & 71 & 102 & 0.004 & 2.437 \\
\hline & & $30,4 \%$ & $69,6 \%$ & $100,0 \%$ & & \\
\hline & Total & 81 & 118 & 199 & & \\
\hline & & $40,7 \%$ & $59,3 \%$ & $100,0 \%$ & & \\
\hline
\end{tabular}

Berdasarkan tabel 1 hasil analisis univariate karakteristik responden 350 orang, 151 orang atau 43,1 $\%$ adalah laki-laki dan 199 orang atau 56,9\% perempuan.
Berdasarkan tabel 2 hasil analisis univariat karakteristik responden smartphone addiction pada remaja 182 orang atau 52,0 \% Positive mengalami smartphone 
addiction dan 168 orang atau 48,0 \% tidak mengalami gangguan psikososial.

Berdasarkan tabel 3 hasil analisis univariat di dapatkan dari 350 orang responden 166 orang atau 47,4 mengalami gangguan psikososial dan 184 orang atau 52,6 tidak mengalami gangguan psiksososial.

Berdasarkan tabel 4 hasil analisis bivariate didapatkan hasil dari remaja laki-laki yang positive smartphone addiction 70,6\% mengalami gangguan psikososial dan $25 \%$ tidak gangguan psikososial sedangkan untuk negative smartphone addiction 37,9\% mengalami gangguan psikososial dan tidak mengalami gangguan psikososial $62,1 \%$ dengan nilai $p$-value 0.000 OR 3,936 dapat di simpulkan bahwa remaja lak-laki positive smartphone addiction beresiko 3,936 kali untuk mengalami gangguan psikososial.

Untuk remaja perempuan didapatkan hasil yang positive smartphone addiction 51.5\% mengalami gangguan psikososial dan 48,5\% tidak mengalami gangguan psikososial, sedangkan untuk negative smartphone addiction didapatkan hasil 30,7 mengalami gangguan psikososial dan $69,6 \%$ tidak mengalami gangguan psikososial dengan nilai p-value 0.004 OR 2,437 dapat di simpulkan bahwa remaja perempuan positive smartphone addiction beresiko 2,437 kali untuk mengalami gangguan psikososial.

Penelitian ini sejalan dengan penelitian yang dilakukan Lukman, (2018), laki-laki lebih beoresik untuk mengalami smartphone addidtion dalam penelitian ini laki-laki lebih banyak menggunakan smartphone untuk bermain game sedangkan perempuan lebih banyak menggunakan smartphone sosial media dan belanja online.

Penelitian yang di India dengan ada hubungan antara smartphone addiction dengan gaya hidup dan role model sedangkan Menurut penelitian yang dilakukan oleh Muflih et al., ( 2017), smartphone addiction mempengaruhi interaksi sosial di SMA N I kalasan Sleman Yogyakarta.

Remaja yang menggunakan smartphone harus dingatkan dengan lama waktu menggunakan, penggunaan dalam jangka waktu yang lama penyebab utama smartphone addiction (Lai, Wong, Pui, \& Lam, 2016), penggunaan yang control akan menimbulkan resiko ke gangguan psikososial (Servet Aker, Mustafa K[rzat yahin, Serap Sezgin, 2017).

Di perlukan peran orang tua dalam mengontrol penggunaan smartphone oleh remaja (Sussman et al., 2017), smartphone juga di gunakan orang tua sebagai alat komunikasi untuk mengontrol remaja (Fadzil, Abdullah, Azul, \& Salleh, 2016).

Dalam mengontrol penggunaan smartphone oleh remaja disamping orang tua sekolah sebagai lingkungan eksternal remaja juga perlu di libatkan dalam mengatasi agar remaja tidak mengalami smartphone addiction. Pihak sekolah bisa mengeluarkan kebijakkan pembatasan penggunaan smartphone di sekolah tentunya perlu dukungan komite sekolah dan orang tua.

Sekolah harus bekerja sama dengan puskesmas setempat untuk optimalkan fungsi Usaha Kesehatan sekolah (UKS) dalam mendeteksi perkembangan psikososial remaja dan mendeteksi remaja dengan smartphone addiction.

\section{SIMPULAN}

Remaja adalah masa yang rentan, sangat mudah menerima budaya baru termasuk perkembangan teknologi smartphone, penggunaan smartphone yang berlebihan akan mempengaruhi perkembangan psikologis remaja yang berefek ke resiko gangguan psikososial pada remaja. Hasil dari penelitian didapatkan bahwa remaja yang positive smartphone addiction lebih beresiko untuk mengalami gangguan psikososial.

Dibutuhkan kerja sama antara pihak sekolah dengan orang tua dalam penggunaan smartphone pada remaja, sekolah mengeluarkan kebijakkan pembatasan penggunaan smartphone pada remaja dan perlu dukungan dari orang tua serta lingkungan sekolah dan komite sekolah.

Sekolah bisa berkerja sama dengan Puskesmas terdekat untuk mengintergrasikan program usaha kesehatan sekolah (UKS) dengan secara rutin untuk memeriksa kesehatan psikologis remaja.

\section{DAFTAR PUSTAKA}

Aboobaker, S., Jangam, K. V, Vijay, K. J., Amaresha, A. C., \& Jose, A. (2019). Predictors of emotional and behavioral problems among Indian adolescents: A clinic-based study. Asian Journal of Psychiatry, 39(October 2018), 104-109. https://doi.org/10.1016/j.ajp.2018.12.002

Abreu, K. s. Y. \& C. N. de. (2011). Internet Addiction (4th ed.). Canada: John Wiley \& Sons, Inc.

Baker, K. D., Den, M. L., Graham, B. M., \& Richardson, R. (2013). Neurobiology of Learning and Memory A window of vulnerability: Impaired fear extinction in adolescence. NEUROBIOLOGY OF LEARNING AND MEMORY. https://doi.org/10.1016/j.nlm.2013.10.009

Cho, K., \& Lee, J. (2017). Computers in Human Behavior In fl uence of smartphone addiction proneness of young children on problematic behaviors and emotional intelligence: Mediating self-assessment effects of parents using smartphones. Computers in Human Behavior, 66, 303-311.

https://doi.org/10.1016/j.chb.2016.09.063

Chung, T. W. H., Sum, S. M. Y., Sc, M. M., Chan, M. W. L., \& Soc, M. S. (2019). Adolescent Internet Addiction in Hong Kong: Prevalence Psychosocial Correlates, and Prevention. Journal of Adolescent Health, 64(6), S34-S43. https://doi.org/10.1016/j.jadohealth.2018.12.016

Comer, M. D. M., \& Kelleher, K. J. (2014). NIH Public Access, 153(3), 254-260.

Fadzil, N. M., Abdullah, M. Y., Azul, M., \& Salleh, M. (2016). THE LEVEL OF TOLERANCE SANCTIONING CHILDREN USING GADGETS BY PARENTS LEAD TO NOMOPHOBIA : EARLY AGE, 09(02), 615-622.

Ferguson, C. J. (2015). Do Angry Birds Make for Angry Children? A Meta-Analysis of Video Game Influences on Children ' $s$ and Adolescents ' Aggression, Mental Health , Prosocial Behavior, and Academic Performance. https://doi.org/10.1177/1745691615592234

Jellinek, S., Biederman, J., Bishop, J., Michael, J., 
Rosenbaum, F., \& Ed, D. (1991). in the Children of Outpatients at a Psychopharmacology Clinic, (August), 1031-1036.

Kwon, M., Kim, D., Cho, H., \& Yang, S. (2013). The Smartphone Addiction Scale: Development and Validation of a Short Version for Adolescents, 8(12), $1-7$. https://doi.org/10.1371/journal.pone.0083558

Lai, I., Wong, K., Pui, M., \& Lam, S. (2016). Gaming behavior and addiction among Hong Kong adolescents. Asian Journal of Gambling Issues and Public Health. https://doi.org/10.1186/s40405016-0016-x

Lee, K., Bejerano, I. L., Han, M., \& Seok, H. (2019). This study was funded by the 2015 Basic Research Programs in Science and Mihwa Han b. Archives of Psychiatric Nursing, \#pagerange\#. https://doi.org/10.1016/j.apnu.2019.01.002

Lukman, M. H. C. (2018). Penggunaan dan adiksi smartphone di kalangan mahasiswa fakultas kedokteran universitas hasanuddin angkatan 2015 dan 2016. Universitas Hasanudin.

Muflih, M., Hamzah, H., \& Puniawan, W. A. (2017). Students' Use Of Smartphones and Social Interaction in SMAN I Kalasan Sleman Yogyakarta, $\mathrm{VIII}(1)$.

Nayak, J. K. (2018). Computers \& Education Relationship among smartphone usage, addiction , academic performance and the moderating role of gender: A study of higher education students in India. Computers \& Education, 123(May), 164173. https://doi.org/10.1016/j.compedu.2018.05.007

Perez, L. G., Conway, T. L., Arredondo, E. M., Elder, J. P., Kerr, J., Mckenzie, T. L., \& Sallis, J. F. (2017). Where and when adolescents are physically active: Neighborhood environment and psychosocial correlates and their interactions. Preventive Medicine, 105(March), 337-344. https://doi.org/10.1016/j.ypmed.2017.10.010

Santrock, J. W. (2014). Adolescence. New York: McGraw-Hill Education, 2 Penn Plaza.

Schneider, M. (2013). Adolescence as a vulnerable period to alter rodent behavior, 99-106. https://doi.org/10.1007/s00441-013-1581-2

Servet Aker, Mustafa K[rzat yahin, Serap Sezgin, G. O. (2017). Psychosocial Factors Affecting Smartphone Addiction in University Students, 28(4), 215-219. https://doi.org/10.1097/JAN.0000000000000197

Sussman, C. J., Harper, J. M., Stahl, J. L., \& Weigle, P. (2017). Inter $\mathrm{n}$ et and Video Game Addictions. Child and Adolescent Psychiatry Clinics of NA. https://doi.org/10.1016/j.chc.2017.11.015

Wayan Diah Anima, W. P. (2014). The Prevalence Of Psychosocial Stress And Affecting Factors Among The Students Xii Grade Science And Social Education At Sman 6 Denpasar.

Wu, A. M. S., Cheung, V. I., Ku, L., \& Hung, E. V. A. P. W. (2013). Psychological risk factors of addiction to social networking sites among Chinese smartphone users, 2(3), 160-166. https://doi.org/10.1556/JBA.2.2013.006
Yeon, J., Yop, J., \& Won, Y. (2018). Child Abuse \& Neglect $E$ ff ect of parental neglect on smartphone addiction in adolescents in South Korea. Child Abuse \& Neglect, 77(December 2017), 75-84. https://doi.org/10.1016/j.chiabu.2017.12.008

Young, K. S. (2015). Addictive Behaviors The evolution of Internet addiction is. Addictive Behaviors, 2014-2015.

https://doi.org/10.1016/j.addbeh.2015.05.016 